\title{
Relatórios de sustentabilidade segundo a Global Reporting Initiative (GRI): uma análise de correspondências entre os setores econômicos brasileiros
}

\author{
Murilo de Alencar Souza Oliveira ${ }^{a *}$, Lucila Maria de Souza Campos ${ }^{\mathrm{b}}$, \\ Simone Sehnem ${ }^{c}$, Adriana Marques Rossetto ${ }^{\mathrm{d}}$ \\ a*murilodealencar@bol.com.br, malencar@fiocruz.br, ENSP/Fiocuz, Brasil \\ blucila@deps.ufsc.br, UFSC, Brasil \\ 'simonesehnem_adm@yahoo.com.br, UNOESC, UNISUL, Brasil \\ damarquesrossetto@gmail.com, UFSC, Brasil
}

\begin{abstract}
Resumo
0 presente artigo tem por objetivo principal apresentar o nível de adesão e o volume de publicações dos relatórios de sustentabilidade das empresas brasileiras conforme as diretrizes da Global Reporting lnitiative (GRI) entre 2000 e 2008. Para a análise, foram definidas 5 variáveis de estudo: i) Setor econômico de atuação das empresas; ii) Ano de adesão às diretrizes; iii) Nível de aplicação das diretrizes; iv) Existência de ações negociadas em segmentos da BM\&FBOVESPA; e v) Participação na composição do índice de sustentabilidade empresarial (ISE) da BM\&FBOVESPA. Quanto aos procedimentos metodológicos, foram aplicadas análises por correspondências simples e múltipla entre os setores de atuação econômica das empresas publicantes e as 5 variáveis de estudos definidas. Os resultados mostram que o universo de organizações que publicaram relatórios socioambientais até 2008 ainda é reduzido. Contudo, observa-se crescente adesão, demonstrada pelo número de publicações, sobretudo na Europa. As empresas brasileiras responderam por metade do volume de publicações em 2008 na América Latina e o setor de energia liderou esse processo no país com 35\% da amostra.
\end{abstract}

Palavras-chave

Relatórios de sustentabilidade. Setores econômicos. Diretrizes GR1.

\section{Introdução}

As questões relacionadas ao meio ambiente e aos impactos negativos causados pelas atividades das empresas passaram a ser um tema recorrente nas mesas de negociações e em fóruns mundiais que tratam do desenvolvimento econômico. As empresas e seus gestores começam a entender e aceitar que possuem obrigações sociais e que necessitam adotar práticas que colaborem com a melhoria das condições dos trabalhadores, clientes, sociedade e do meio ambiente. Mesmo que essas práticas onerem seus orçamentos, assumem

[...] obrigações de caráter moral, além das estabelecidas em lei, mesmo que não diretamente vinculadas a suas atividades, mas que possam contribuir para o desenvolvimento sustentável dos povos [...] (ASHLEY, 2002, p. 6)

e "[...] que podem ajudar a sociedade mesmo que não contribuam diretamente para o lucro da empresa." (CERTO; PETER, 1993, p. 279).

Esse processo de consciência empresarial, com a adoção de posturas mais proativas, tem ocorrido pelas pressões competitivas e pelo aumento do rigor legal. A sociedade, por sua vez, vem demandando também maior transparência (MELÉ; DEBELJUH; ARRUDA, 2006; CORNELIUS; WALLACE; TASSABEHJI, 2007). 0 fato é que existem empresas que entendem a importância de internalizar a temática da sustentabilidade e passam 
[...] a adotar estratégias que consideram a preservação ambiental, a transparência das ações empresariais, a responsabilidade com o crescimento econômico do país e o compromisso com o bem-estar social. (AZEVED0, 2006, p. 76).

Souza, Andrade e Cândido (2008) destacam a necessidade de engajamento da sociedade civil organizada, governos e empresas no exercício da responsabilidade compartilhada, mediante maior transparência e disponibilidade de informações sobre ações e atividades empreendidas e entre os organismos institucionais, a fim de criar bases sólidas para um desenvolvimento local sustentável.

A publicação de balanços sociais ou relatórios de sustentabilidade empresariais tem servido como forma de demonstrar os desempenhos das empresas (iniciativas, resultados, atitudes e investimentos), por meio do uso de vários indicadores ou parâmetros, em prol do desenvolvimento sustentável (MARIMON et al., 2012). Esses relatórios são demonstrativos anuais dos projetos, benefícios e ações sociais dirigidos a todos os stakeholders (públicos de interesse): empregados, investidores, governos, mercado, acionistas e comunidade (ETHOS, 2009). A função é tornar públicas a responsabilidade e preocupação da empresa em relação às pessoas e à vida no planeta, construindo vínculos integrativos fortes com a sociedade. Conforme salienta Azevedo (2006), as empresas interiorizam o desenvolvimento sustentável como estratégia de negócios e continuam a ter o lucro como objetivo principal, porém passam a considerar a mitigação dos impactos de suas atividades em prol dos funcionários e da sociedade.

A adesão das organizações empresariais aos padrões de publicação de relatórios de sustentabilidade nos moldes da GRl tem crescido no mundo todo (MARIMON et al., 2012; SKOULOUDIS; EVANGELINOS; KOURMOUSIS, 2009; PRADO-LORENZO; GALLEGOALVAREZ; GARCIA-SANCHEZ, 2009; BROWN; DE JONG; LEVY, 2009; LEVY; SZEJNWALD-BROWN; DE JONG, 2010) e também no Brasil (ANDRADE; GOSLING; XAVIER, 2010; GASPARINO; RIBEIRO, 2007; MELÉ; DEBELJUH; ARRUDA, 2006), porém surgem algumas questões como: será que no Brasil existem setores econômicos mais avançados nesse processo? No caso brasileiro, as organizações pioneiras em publicar relatórios são aquelas que o fazem de modo mais completo e adequado às diretrizes da GRI? Será que ter ações negociadas em bolsa de valores gera maior interesse em publicar relatórios de sustentabilidade? As organizações que publicam relatórios em atendimento às diretrizes GRI estão na composição do índice de sustentabilidade empresarial (ISE) da BM\&FBOVESPA - Bolsa de Valores, Mercadorias e Futuros S.A.?

Visando responder a esses questionamentos, o presente artigo tem por objetivo principal apresentar o nível de adesão e o volume de publicações dos relatórios de sustentabilidade das empresas brasileiras conforme as diretrizes da Global Reporting Initiative (GRI) no período de 2000 a 2008. Para tanto, foram definidas 5 variáveis de estudo: i) Setor econômico de atuação das empresas; ii) Ano de adesão às diretrizes; iii) Nível de aplicação das diretrizes; iv) Existência de ações negociadas em segmentos da BM\&FBOVESPA; e v) Participação na composição do índice de sustentabilidade empresarial (ISE) da BM\&FBOVESPA.

A escolha das diretrizes definidas pela GRl ocorreu em função desta ser uma iniciativa de reconhecimento internacional e apoiada por importantes organizações, como a Organização das Nações Unidas (ONU), no plano mundial, e o Instituto Ethos de Empresas e Responsabilidade Social (que adotou o GRI) e o governo federal, no plano nacional. Foram ainda utilizados dados sobre as empresas que possuem ações negociadas em bolsas de valores no país, bem como os diferentes segmentos de listagem e índices de ações existentes (BOVESPA, 2009; BM\&FBOVESPA, 2009).

Com relação ao volume de publicações dos relatórios, procurou-se destacá-lo em relação ao total de publicações no mundo e na América Latina, bem como: identificar possíveis correspondências entre os setores de atuação das empresas no Brasil que publicaram relatórios de sustentabilidade no padrão GRl em 2008, com o ano de adesão, o nível de aplicação das diretrizes da GRl e participação nos diferentes segmentos de negociação e/ou composição do índice de sustentabilidade empresarial (ISE) da BM\&FBOVESPA. Dessa forma acredita-se que este trabalho possa contribuir para os estudos sobre os indicadores GRl, à medida que traz um panorama da utilização desses indicadores no Brasil, tal como apresentado em outros estudos no mundo (DAUB, 2007; GASPARINO; RIBEIRO, 2007; PARK; BRORSON, 2005).

Este artigo possui, além desta introdução, mais 4 outros tópicos. 0 primeiro trata dos pressupostos teóricos que alicerçam o artigo. 0 segundo apresenta os procedimentos metodológicos utilizados para alcançar os objetivos delineados. 0 terceiro apresenta os principais resultados, e o quarto, as conclusões do artigo.

\section{Pressupostos teóricos}

\subsection{A sustentabilidade nos relatórios e indicadores corporativos}

A identificação dos fatores relativos ao desenvolvimento sustentável tornou necessária a criação de mecanismos e maneiras que apontem, indiquem, anunciem ou estimem os níveis e impactos das atividades humanas, bem como suas possiveis tendências de ocorrência. Para tanto, foram criados 
índices e indicadores de sustentabilidade (BELLEN, 2007). Observa-se, de modo especial nas empresas de grande porte, a utilização de diretrizes para a elaboração de relatórios de sustentabilidade, tais como as definidas para a escolha de indicadores corporativos gerais apresentados, por exemplo, pelo International Institute for Sustainable Development (2005); a Global Reporting Initiative (2006), o Instituto Ethos (ETHOS, 2008), pelos autores Sikdar (2003); Krajnc e Glavic (2005); Labuschagne, Brent e Erck (2005) e Searcy, Karapetrovic e McCartney (2005), entre outros.

Alguns indicadores tornaram-se bastante conhecidos: produto interno bruto (PIB), índice de desenvolvimento humano (IDH), índice de sustentabilidade ambiental (ISA), indice de Gini etc. Todavia, o reconhecimento da importância, sobre ao que se referem e como podem colaborar para a melhoria da sociedade mundial, passa longe da compreensão da maioria das pessoas.

A verdade é que os atuais relatórios de sustentabilidade, apesar de suas virtudes, frequentemente não conseguem atingir públicos-alvo [...] (SUSTAINABILITY...; FUNDAÇÃO...; PROGRAMA..., 2008, p. 24),

e penetrar no nível de entendimento da população.

Nessa lógica da sustentabilidade e da definição de indicadores, surgem ideias e práticas em todo o mundo. As principais bolsas de valores do mundo, por exemplo, modificaram suas atividades e implantaram métodos para valorizar as práticas empresariais sustentáveis e minimizar os impactos ambientais (econômico, natural e social), como: criação de segmentos de negociação de ativos financeiros de empresas com boas práticas de governança corporativa; maior rigor na fiscalização e divulgação de informações e fatos administrativos das empresas, e de medidas e índices de ações de empresas atuantes em prol da sustentabilidade planetária.

\subsection{Global Reporting Initiative (GRI)}

Dentre as principais iniciativas para a elaboração de relatórios de sustentabilidade destaca-se a GRI (SKOULOUDIS; EVANGELINOS; KOURMOUSIS, 2009; PRADO-LORENZO; GALLEGO-ALVAREZ; GARCIASANCHEZ, 2009; BROWN; DE JONG; LEVY, 2009; LEVY; SZEJNWALD-BROWN; DE JONG, 2010), que é considerada como um dos mais consistentes esforços para consolidar as diversas iniciativas existentes para se chegar a um consenso sobre a avaliação de sustentabilidade empresarial (ALMEIDA, 2002; OLIVEIRA et al., 2009; BASSETTO, 2010). Seus esforços de atuação são apontados como uma possível razão do crescimento da quantidade de relatórios de sustentabilidade empresariais publicados no país
(SUSTAINABILITY...; FUNDAÇÃO...; PROGRAMA..., 2008).

A Global Reporting Initiative (GRI) é uma organização sem fins lucrativos, criada em 1997 por meio de uma ação conjunta da Coalizition for Environmentally Responsible (CERES) e do PNUMA, com o objetivo de contribuir para a melhoria dos relatórios de sustentabilidade emitidos pelas organizações e estimular a adoção voluntária de indicadores com maior qualidade, rigor e aplicação global, para tornar tal prática mais harmonizada internacionalmente. Esses relatórios requerem a elaboração com base nos princípios da transparência, abrangência, relevância, verificabilidade, neutralidade, exatidão, objetividade, facilidade de compreensão, dentre outros (GLOBAL..., 2006).

Em 1999, houve o lançamento da primeira versão das diretrizes para relatórios de sustentabilidade (G1) da GRl, um guia de apresentação dos principais indicadores de desempenho de uma organização nas esferas econômica, social e ambiental. Em 2000, primeiro ano de vigência, apenas 10 empresas de 9 setores publicaram relatórios nesse padrão (GLOBAL..., 2006): 4 americanas (automotivo, químico, produtos farmacêuticos e produtos de consumo); 2 suecas (eletrodomésticos e materiais de construção); 1 canadense (energia); 1 inglesa (aviação); 1 japonesa (bens duráveis); e outra sul-africana (químico).

Decorrida mais de uma década de publicação dos primeiros relatórios no modelo GRl, as diretrizes para relatórios de sustentabilidade foram bastante aprimoradas. Em 2002, houve a publicação de sua segunda versão (G2), e em 2006 houve o lançamento da terceira versão (G3), contendo mais de 100 indicadores a serem apresentados pelas empresas em seus relatórios. No início de 2011, foi lançada uma revisão da terceira versão (G3.1), que inclui indicadores de performance relativos aos impactos aos direitos humanos, à comunidade local e de gênero (GLOBAL..., 2012). Como este estudo se restringiu à análise dos relatórios publicados até 2008, não contempla a versão G3.1 das diretrizes.

Cada versão foi elaborada para ampliar as condições de garantia da qualidade, aplicabilidade, padronização e credibilidade dos relatórios publicados pelas organizações, bem como aumentar o grau de exigência e confiança do conteúdo destes relatórios.

\subsection{Relatórios e indicadores corporativos de sustentabilidade no Brasil}

No Brasil, a BM\&FBOVESPA S.A. - Bolsa de Valores, Mercadorias e Futuros tem procurado atuar no rumo da sustentabilidade das empresas no país, por isto implantou o índice de sustentabilidade 
empresarial (ISE), o novo mercado e os segmentos diferenciados de governança corporativa. Atos estes que confirmam o compromisso demonstrado em sua missão institucional com atitudes socialmente responsáveis (BM\&FBOVESPA, 2009).

0 ISE é um índice que avalia o desempenho das empresas emissoras das 150 ações mais negociadas na BOVESPA e visa tornar-se um referencial para os investidores financeiros que procuram aplicações em empresas socialmente responsáveis, sustentáveis e rentáveis. Surgiu de uma iniciativa conjunta da BOVESPA com várias instituições associativas do mercado de capitais, o Instituto Ethos, o Instituto Brasileiro de Governança Corporativa (IBGC), o Ministério do Meio Ambiente e passou a contar ainda com o Programa das Nações Unidas para o Meio Ambiente (PNUMA). 0 ISE tem por objetivo refletir o retorno teórico de uma carteira de ações de empresas com reconhecido comprometimento com a responsabilidade social e a sustentabilidade empresarial, e também atuar como promotor de práticas empresariais sustentáveis. As empresas para terem suas ações no ISE necessitam apresentar indicadores de desempenho que atendam a 6 critérios: ambientais; sociais; econômico-financeiros; gerais (posição da empresa perante acordos globais e se publica balanços sociais); de natureza do produto (os possíveis danos e riscos à saúde dos consumidores acarretados pelo consumo/uso dos produtos da empresa, entre outros) e de governança corporativa.

Outro exemplo é o índice de ações com governança corporativa diferenciada (IGC), que foi criado para medir o desempenho de uma carteira teórica composta por ações de empresas que aderiram ao novo mercado e seus segmentos diferenciados. A BOVESPA (2009) informa que são segmentos de listagem destinados à negociação de ações de empresas que se comprometem, voluntariamente, com a adoção de práticas de governança corporativa (transparência, prestação de contas, equidade e responsabilidade corporativa) adicionais em relação às exigências da legislação brasileira. Essas práticas facilitam acompanhar e fiscalizar os atos da administração e dos controladores da companhia e a adoção de regras societárias que equilibram os direitos de todos os acionistas, reduzem as incertezas no processo de avaliação e o risco para os investidores e para a sociedade em geral.

As iniciativas descritas são positivas e incentivam novas práticas sustentáveis (BASSETTO, 2010; ANDRADE; GOSLING; XAVIER, 2010), porém cabe crítica quanto ao excesso de métodos e indicadores desenvolvidos, focados na identificação de algum aspecto específico ou complementar a outros (OLIVEIRA et al., 2009; ANDRADE; GOSLING; XAVIER, 2010).

\subsection{Estudos sobre relatórios e indicadores corporativos de sustentabilidade}

Diversos estudos sobre os tipos de relatórios e indicadores corporativos de sustentabilidade têm sido realizados pelo mundo (LEVY; SZEJNWALDBROWN; DE JON, 2010; BROWN; DE JONG; LEVY, 2009; DAUB, 2007; GASPARINO; RIBEIRO, 2007; PARK; BRORSON, 2005). Gasparino e Ribeiro (2007), por exemplo, desenvolveram trabalho de comparação entre os relatórios sociais brasileiros e americanos, para identificar diferenças comportamentais e de evidenciação. A base de consulta foram 6 empresas do setor de papel e celulose (3 americanas e 3 brasileiras). Os autores constataram que as empresas americanas adotaram as diretrizes GRl, além de terem maior riqueza de dados, ainda que não conseguissem atender na íntegra as diretrizes GRI; enquanto dentre as empresas brasileiras, somente uma teve seu relatório verificado por auditoria externa. Em todos os relatórios analisados foi constatada ausência de informações financeiras. Outro fator comum foi que todas as empresas apresentaram certificações ambientais (ISO 14001) e que as empresas americanas possuíam florestas certificadas pela Sustainable Forestry Initiative (SFI).

Ferreira et al. (2009) desenvolveram uma pesquisa para identificar as relações entre os indicadores definidos pelo Instituto Brasileiro de Análises Sociais e Econômicas (lbase), um dos principais relatórios de responsabilidade social no Brasil, com o GRI. A ênfase de ambos os modelos recai sobre os indicadores sociais, haja vista que o surgimento do balanço social foi para atender uma demanda de informações relativas às relações sociais entre a entidade e seus stakeholders.

Os relatórios de sustentabilidade das empresas do setor elétrico da América do Sul, elaborados com base na terceira versão das diretrizes da GRI (G3), foram analisados por Castro, Siqueira e Macedo (2009), que calcularam os graus de aderência plena (GAPIE) e de evidenciação efetiva (GEE). Os autores verificaram o quanto do requerido nos indicadores essenciais foi atendido e o potencial dessas informações que foi efetivamente apresentado. Verificaram que nenhuma das empresas apresentou alto GAPIE, nem GEE. Os piores desempenhos foram na área social, enquanto os melhores GAPIE e GEE estavam nas áreas ambiental e econômica, respectivamente, o que evidencia que ainda é preciso evoluir bastante na demonstração do real nível de responsabilidade socioambiental. Entre a primeira e a última colocada existe um distanciamento significativo (57\% e 6\%), o que caracteriza que elas se encontram em estágios bem distintos de aderência às diretrizes da versão $\mathrm{G} 3$. 
Também Park e Brorson (2005) exploraram o desenvolvimento de relatórios de sustentabilidade ambiental na Suécia e a dinâmica subjacente à decisão corporativa para introduzir ou não a garantia de terceiros nos relatórios voluntários. Os resultados foram baseados em entrevistas com 28 empresas suecas, na análise da sustentabilidade ambiental das empresas pelos relatórios anuais, bem como entrevistas com prestadores de seguros, ou melhor, os auditores externos. Entre 1990 e 2003, o número de relatos de voluntariado corporativo aumentou e, até 2003, aproximadamente um terço dos relatórios foi sujeito à avaliação de terceira parte para aumentar sua fidedignidade. Em geral, as empresas asseguradas foram positivas em relação à percepção dos benefícios da terceira parte.

Daub (2007), em estudo de grande repercussão, buscou analisar quantitativa e qualitativamente os relatórios de sustentabilidade corporativos emitidos pelas empresas da Suíça. 0 autor entrevistou 25 gestores de empresas, utilizando o ano de 2002 como base de análise dos relatórios de sustentabilidade. Os achados da pesquisa evidenciam que, se o pesquisador não tivesse incluído os relatórios anuais da empresa, não teria tido acesso a importantes informações não presentes nos relatórios de sustentabilidade. Diversas empresas cujos relatórios eram comparativamente pobres atingiram a contagem total de pontos em alguns critérios e também apresentaram todas as informações requeridas pelo modelo de elaboração utilizado. De forma geral, os relatórios impressos seguem as orientações das diretrizes GRl. A fraqueza evidente de todos os relatórios consistiu na apresentação de indicadores de desempenho, pois dos 76 analisados apenas 33\% atenderam esse quesito. Isso evidencia que ainda há uma árdua caminhada por parte das empresas para incorporar essas informações em seus relatórios de sustentabilidade.

Igualmente, Pereira, Faria e Souza (2009) analisaram os indicadores que são priorizados no segmento químico e petroquímico, para avaliar as dimensões econômica, social e ambiental da sustentabilidade. Os procedimentos metodológicos adotados no trabalho consistiram de pesquisa bibliográfica sobre indicadores de sustentabilidade, seguida de pesquisa documental realizada nos relatórios disponíveis nos websites das empresas classificadas pela revista Exame como sendo as maiores em faturamento, no referido segmento, nos anos de 2006 e 2007. Constataram a existência de grande diversidade de modelos e indicadores utilizados por essas empresas. Após criteriosa análise, concluíram que essa variedade dificulta a comparação entre os mesmos. Não obstante, como ponto de convergência dos relatórios, verificou-se a constante presença de indicadores que abarcam as dimensões essenciais destacadas pelos autores estudados na revisão conceitual da plataforma teórica: econômica, social e ambiental.

Observa-se, portanto, que o tema vem sendo discutido e pesquisado, assim como cresce cada vez mais o interesse das empresas por divulgar suas informações relacionadas às práticas de responsabilidades socioambientais.

\section{Procedimentos metodológicos}

Este trabalho efetuou uma análise descritiva, com abordagem quantitativa e qualitativa. Foi baseado em pesquisa documental, com utilização de dados secundários constantes de listagens sobre o total da publicação de relatórios de sustentabilidade nos padrões da GRl, no período de 1999 a 2008 (GLOBAL..., 2009).

Os procedimentos de trabalho iniciaram com a identificação e análise quantitativa da evolução anual da publicação de relatórios de sustentabilidade empresariais no padrão GRl no mundo, bem como dos setores de atuação das empresas publicantes. Esta etapa ocorreu a partir de levantamento dos dados constantes dos 3.387 relatórios disponibilizados em GRI (GLOBAL..., 2009) e posterior consolidação em planilhas eletrônicas Excel, elaboradas por região/ continente de publicação dos relatórios. Isso permitiu analisar a evolução anual do total dos relatórios por cada região/continente (África, América Latina, América do Norte, Ásia, Europa e Oceania), assim como observar quais foram os principais países em número de relatórios publicados no mundo no período considerado.

Em seguida, o foco do trabalho foi analisar a evolução anual e o total de relatórios publicados em cada um dos países da América Latina, bem como identificar o total de empresas publicantes e quais os setores em que atuam. Também foi realizada uma comparação entre a evolução anual e o total publicado de relatórios no Brasil com os demais países da região.

$\mathrm{Na}$ etapa posterior de trabalho, foi realizada uma análise sobre as informações constantes em GRI (GLOBAL..., 2009) sobre a publicação de relatórios de sustentabilidade empresariais no padrão GRI pelas empresas no Brasil. Para tal foram elaboradas planilhas contendo informações sobre os 148 relatórios publicados por 79 empresas no país. Tais informações foram referentes a: ano de publicação; versão da diretriz adotada; nível de aderência ou aplicação das diretrizes; e setor de atuação das empresas.

Após, foi realizada pesquisa para identificar quais empresas publicantes de relatórios no padrão da GRI no ano de 2008 tinham ações listadas na Bolsa de Valores 
de São Paulo (BOVESPA) e se constavam na composição do índice de sustentabilidade empresarial (ISE) da BM\&FBOVESPA (2009). Com essas informações foi possível iniciar o tratamento e análise dos dados referentes às publicações dos relatórios no Brasil. Para tal, foram empregadas as técnicas de estatística descritiva e de análise multivariada de dados.

Foi aplicada a análise por correspondência simples entre os setores de atuação econômica das empresas publicantes de relatórios de sustentabilidade no Brasil com: o ano de adesão; os segmentos de negociação das ações na bolsa de valores; e o nível de aplicação das diretrizes GRI. E também entre o ano de adesão às diretrizes GRl e o nível de aplicação ao modelo GRl. Foi ainda aplicada a análise por correspondência múltipla entre: setor de atuação; ano de adesão; nível de aplicação das diretrizes; segmento de negociação e pertencimento ao ISE da BM\&FBOVESPA (2009). A utilização ocorreu pela possibilidade de identificar possíveis relações entre as múltiplas variáveis deste estudo e por ser a mais indicada para se trabalhar com a interligação simultânea entre variáveis nominais ou qualitativas (MINGOTI, 2005; HAIR JUNIOR et al., 2005).

Dessa forma, foi utilizada uma matriz de Burt (21 linhas x 21 colunas) - que consiste em uma matriz simétrica com todos os cruzamentos possíveis - entre as 5 variáveis de estudo, com base no ano de 2008, que foram:

a) Setor econômico das empresas, com 8 categorias = energia (Ener), bancário (Banc), mineração (Mine), bens de consumo (BCon), indústria da construção (lnCo), papel e celulose (PCel), serviços (Serv) e outros (Outr);

b) Nível de aderência ou aplicação dos relatórios de sustentabilidade publicados, na terceira versão das diretrizes (G3). Os relatórios são classificados em 3 níveis de aderência ou aplicação numa abordagem crescente de $\mathrm{C}$ até $\mathrm{A}$, conforme o padrão de divulgação relativo: ao perfil do relatório, às formas de gestão e aos indicadores de desempenho apresentados. Ocorre que algumas empresas não atenderam a todas estas condições ou estão em processo de adequação de seus relatórios, sendo estes considerados como não declarados (D);

c) Ano de adesão às diretrizes da GRI, com 4 categorias $=2005,2006,2007$ e 2008, sendo que a primeira agrupa as empresas publicantes até 2005 ;

d) Empresas com ações negociadas na BM\&FBOVESPA, com 3 categorias: pertencentes ao segmento do novo mercado, com boas práticas de governança corporativa ( $1 \mathrm{GC})$; com ações negociadas apenas no segmento tradicional da bolsa (MTD); e com capital fechado ou capital aberto, mas que não possuem ações negociadas na bolsa (NL);

e) Empresas que compõem o índice de sustentabilidade empresarial (ISE) da BM\&FBOVESPA, com 2 categorias: compor (ISE1) ou não compor esse índice (ISE0) no período de dezembro/08 a novembro/09.

Por fim, houve emprego de planilhas eletrônicas Excel para elaboração da base de dados e melhor clareza na comparação dos dados analisados, além do software Statistica versão 6.0 para apresentação gráfica.

\section{Apresentação dos resultados e discussão}

\subsection{A adesão mundial ao modelo GRI}

A partir dos dados de GRI (GLOBAL..., 2009) foi efetuada a identificação e análise da evolução anual, quantitativa e geográfica dos relatórios de sustentabilidade publicados no padrão GRI nas diferentes regiões mundiais, no período de 1999 a 2008, conforme demonstrado na Figura 1.

A relevância da adoção das diretrizes da GRI no cenário mundial pode ser observada pelo número de relatórios de sustentabilidade publicados ao longo de

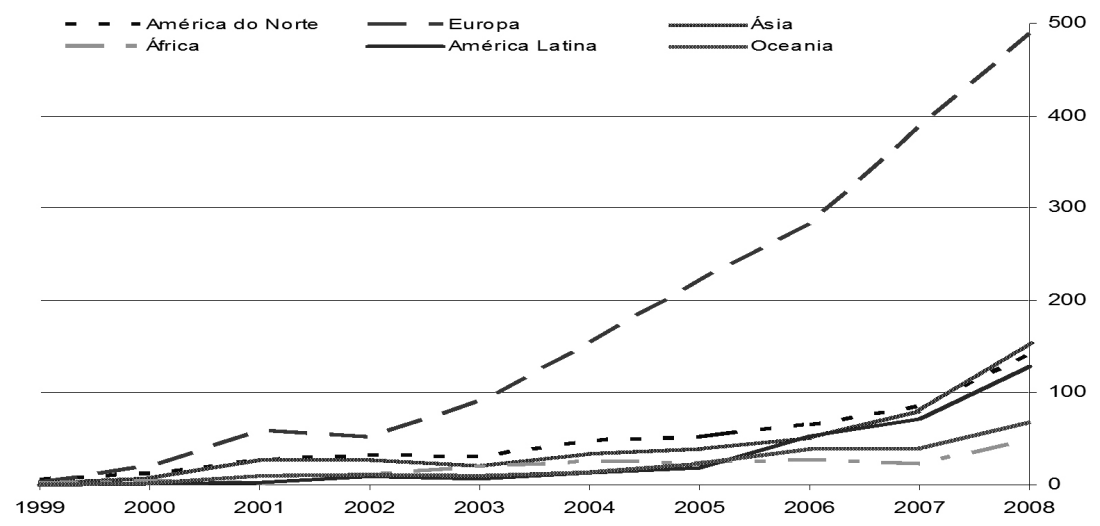

Figura 1. Evolução anual de relatórios de sustentabilidade publicados por continente. Fonte: dados da GRI (GLOBAL..., 2009). 
uma década: 3.387 no total. A Figura 1 mostra também que a publicação de relatórios de sustentabilidade no padrão GRI tem sido crescente no mundo, com a seguinte distribuição: Europa (52\%), América do Norte (14,7\%), Ásia (12,9\%), América Latina $(8,9 \%)$, Oceania $(6,2 \%)$ e África $(5,4 \%)$. Cabe destaque para as empresas europeias, sobretudo a partir de 2002, que lideram o processo. Nas demais regiões houve crescimento também, mais pronunciado a partir de 2005. No ano de 2008 foram 1.031 relatórios publicados, com destaque para Ásia e América Latina.

\subsection{A adesão ao modelo GRI no Brasil e na América Latina}

A partir dos dados de GRI (GLOBAL..., 2009) foi efetuada a identificação e análise comparativa da evolução de relatórios de sustentabilidade publicados no padrão GRI na América Latina e no Brasil, no período de 2000 a 2008, conforme demonstrado na Tabela 1 e na Figura 2.

A Tabela 1 evidencia que as empresas latinoamericanas demonstraram forte adesão à publicação

Tabela 1. Publicação de relatórios de sustentabilidade (GRI) na América Latina.

\begin{tabular}{cccc}
\hline ORDEM & PAÍs & No RELATÓRIOS & No EMPRESAS \\
\hline 1 & Brasil & 148 & 79 \\
2 & Chile & 65 & 41 \\
3 & México & 18 & 14 \\
4 & Colômbia & 17 & 8 \\
5 & Peru & 17 & 8 \\
6 & Argentina & 12 & 7 \\
7 & Equador & 10 & 7 \\
8 & Bolívia & 4 & 2 \\
9 & Venezuela & 4 & 2 \\
10 & Costa Rica & 3 & 3 \\
11 & Panamá & 3 & 1 \\
TOTAL & & 301 & 172 \\
\hline
\end{tabular}

Fonte: dados GRI (GLOBAL..., 2009). de relatórios segundo as diretrizes GRI, no período considerado, com um total de 301 relatórios de sustentabilidade de 172 diferentes organizações da região. Quanto à identificação dos setores de atuação das organizações, $60 \%$ do total pertencem aos segmentos de energia, mineração, bancário, indústria da construção e bens de consumo, respectivamente nessa ordem de importância.

0 Brasil teve a liderança na publicação na região, com metade $(49,2 \%)$ do total de relatórios publicados e 45,9\% das empresas. 0 Chile é o segundo país na região em número de publicações de relatórios de sustentabilidade empresariais no decorrer do período considerado (21,6\%), bem abaixo do total brasileiro. Cabe destacar a fraca adesão por parte das empresas do México $(8,1 \%)$ e Argentina $(4,1 \%)$, países de forte peso econômico na região.

A Figura 2 reforça a forte tendência de crescimento regional a partir de 2006 e a predominância das empresas brasileiras na publicação de relatórios de sustentabilidade no padrão da GRI. No período analisado, somente nos anos de 2006 e 2007, a soma de publicações nos demais países latino-americanos superou o volume brasileiro.

\subsection{Análise da publicação de relatórios de sustentabilidade (GRI) no Brasil}

Em nível mundial, o Brasil ocupou o terceiro lugar em número de publicações no ano de 2008, com 67 relatórios, superado por Espanha (128) e EUA (103). 0 total de relatórios publicados no país (148) representou 4,4\% do total mundial nos 10 anos das diretrizes da GRI, $8^{\circ}$ lugar entre 68 nações, à frente de países como Alemanha - $9^{\circ}$ (138), Canadá - $10^{\circ}$ (138), Itália - $11^{\circ}(125)$ e França - $12^{\circ}$ (108).

Os dados denotam uma importante participação das empresas atuantes no Brasil quanto ao volume de publicações de relatórios no mundo. Contudo, essa

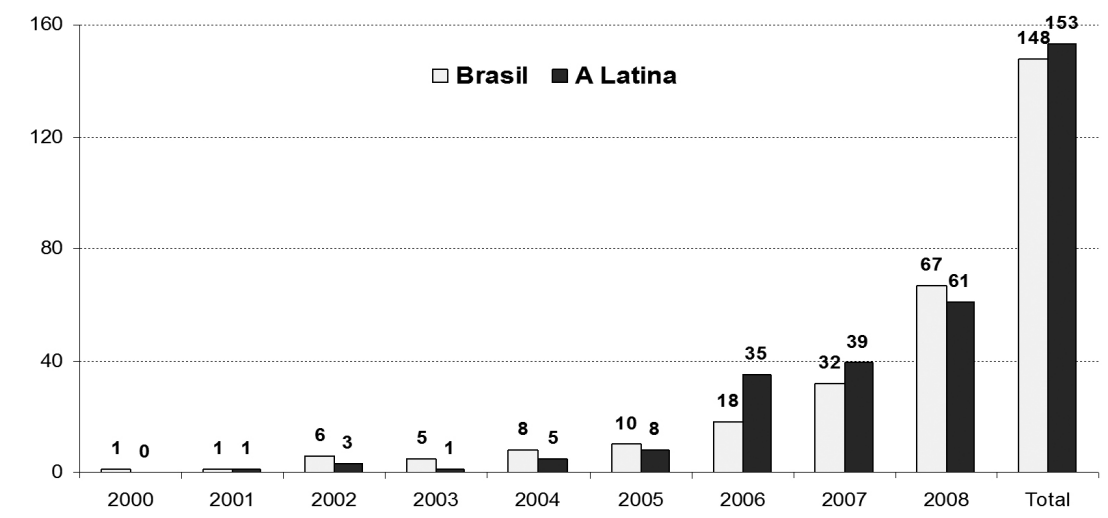

Figura 2. Evolução anual de relatórios publicados - Brasil x América Latina. Fonte: dados GRl (GLOBAL..., 2009). 
importância e o crescimento de adesão das empresas que atuam no Brasil aos padrões de publicação de relatórios de sustentabilidade nos moldes da GRI geram questionamentos: será que ocorre a mesma disseminação nos diversos setores econômicos no país? Existem setores mais avançados nesse processo? As empresas pioneiras em publicar relatórios são as que o fazem de modo mais completo e adequado às diretrizes da GRI? Será que ter ações negociadas em bolsas de valores gera correspondente maior interesse em publicar relatórios de sustentabilidade? As empresas que publicam relatórios em atendimento às diretrizes GRI também são selecionadas para composição do indice de sustentabilidade empresarial (ISE)?

Para tentar responder a essas questões foram efetuadas análises de correspondência (simples e múltipla), com uso de uma matriz de Burt (21 linhas x 21 colunas), por meio do cruzamento entre as 5 variáveis de estudo:

- Setor econômico das empresas, com 8 categorias - dos 67 relatórios de sustentabilidade publicados no Brasil no modelo em análise em 2008 (GLOBAL..., 2009), identificou-se uma amostra de 57 empresas, sendo: 23 empresas no setor de energia (Ener); 6 no bancário (Banc); 3 de mineração (Mine); 4 de bens de consumo (BCon); 4 na indústria da construção ( $\operatorname{lnCo}$ ); 3 de papel e celulose (PCel); 3 em serviços (Serv); e 11 outros (Outr) setores que tiveram somente uma ocorrência;
- Nível de aderência ou aplicação dos relatórios de sustentabilidade publicados até 2008, com 4 categorias $=\mathrm{A}, \mathrm{B}, \mathrm{C}$ e $\mathrm{D}$, conforme o padrão de divulgação relativo ao perfil do relatório, às formas de gestão e aos indicadores de desempenho apresentados;

- Ano de adesão às diretrizes da GRI (4 categorias) - até 2005, 2006, 2007 e 2008;

- Empresas com ações negociadas na BM\&FBOVESPA (3 categorias) - com boas práticas de governança corporativa (IGC); no segmento tradicional da bolsa (MTD); e que não possuem ações listadas na bolsa $(\mathrm{NL})$;

- Empresas com ações no índice de sustentabilidade empresarial (ISE) da BM\&FBOVESPA (2 categorias) - definida em termos de compor (ISE1) ou não compor o índice (ISE0).

A condição de publicação de relatório de sustentabilidade no ano de 2008 foi tomada como referência para análise dos setores econômicos das empresas, em face de ser o ano com o maior número de relatórios publicados e de empresas publicantes e, ainda, da consolidação da $3^{\mathrm{a}}$ versão das diretrizes da GRI (G3) no país.

A Tabela 2 apresenta as coordenadas e contribuições de cada categoria das variáveis.

A Tabela 2 mostra uma contribuição equilibrada para o primeiro fator, com predominância de: setor, nível de aplicação e ano de adesão, total de 65,31\%.

Tabela 2. Coordenadas e contribuições das 5 variáveis analisadas.

\begin{tabular}{|c|c|c|c|c|c|c|c|}
\hline & & Coord 1 & Coord 2 & $\begin{array}{c}\text { Contribuição } \\
\text { absoluta }\end{array}$ & Cosseno 1 & Inércia 2 & Cosseno 2 \\
\hline \multirow{9}{*}{ SETOR } & BCon & $-1,09137$ & 0,47990 & 0,056694 & 0,136287 & 0,012780 & 0,026352 \\
\hline & Ener & $-0,18306$ & $-0,18517$ & 0,006174 & 0,022100 & 0,007364 & 0,022612 \\
\hline & $\ln \mathrm{Co}$ & 0,08204 & $-1,41507$ & 0,000163 & 0,000372 & 0,056640 & 0,110583 \\
\hline & Banc & $-0,26768$ & 0,42327 & 0,001755 & 0,003997 & 0,005116 & 0,009993 \\
\hline & Mine & 1,20030 & 0,41871 & 0,130607 & 0,350214 & 0,018530 & 0,042617 \\
\hline & PCel & $-0,81149$ & $-0,98238$ & 0,021911 & 0,050918 & 0,037437 & 0,074621 \\
\hline & Serv & $-0,33869$ & $-0,23795$ & 0,002889 & 0,006590 & 0,001663 & 0,003253 \\
\hline & Outr & 0,50041 & 1,06104 & 0,008486 & 0,019749 & 0,044481 & 0,088789 \\
\hline & & Contribuição & acumulada & 0,228678424 & & 0,1840099 & \\
\hline \multirow{5}{*}{ ADESÃO } & 2005 & $-1,25839$ & $-0,19154$ & 0,102940 & 0,258265 & 0,002781 & 0,005984 \\
\hline & 2006 & $-0,89876$ & $-0,16175$ & 0,032539 & 0,076868 & 0,001229 & 0,002490 \\
\hline & 2007 & $-0,17057$ & $-1,17119$ & 0,002848 & 0,007788 & 0,156550 & 0,367187 \\
\hline & 2008 & 0,51728 & 0,51311 & 0,069680 & 0,342945 & 0,079933 & 0,337440 \\
\hline & & contribuição & acumulada & 0,208005901 & & 0,2404922 & \\
\hline \multirow{5}{*}{ APLICAÇÃO } & A & 0,05816 & $-0,86549$ & 0,000547 & 0,001814 & 0,141322 & 0,401689 \\
\hline & B & $-1,06066$ & $-0,04821$ & 0,136559 & 0,399058 & 0,000329 & 0,000824 \\
\hline & C & 0,72670 & 0,72075 & 0,030139 & 0,074140 & 0,034565 & 0,072931 \\
\hline & D & 0,63144 & 0,84966 & 0,049166 & 0,144488 & 0,103785 & 0,261610 \\
\hline & & contribuição & acumulada & 0,216410879 & & 0,2800009 & \\
\hline \multirow{4}{*}{ BOLSA } & IGC & $-0,68424$ & 0,71655 & 0,076230 & 0,253453 & 0,097466 & 0,277958 \\
\hline & MTD & 0,68732 & $-0,40085$ & 0,092490 & 0,345369 & 0,036676 & 0,117470 \\
\hline & $\mathrm{NL}$ & $-0,22060$ & $-0,36379$ & 0,005109 & 0,014246 & 0,016197 & 0,038741 \\
\hline & & contribuição & acumulada & 0,173828682 & & 0,1503401 & \\
\hline \multirow{3}{*}{ 1SE } & 1SE1 & 0,36360 & $-0,30839$ & 0,045260 & 0,373341 & 0,037959 & 0,268570 \\
\hline & ISE0 & $-1,02680$ & 0,87089 & 0,127816 & 0,373341 & 0,107198 & 0,268570 \\
\hline & & contribuição & acumulada & 0,173076114 & & 0,1451568 & \\
\hline
\end{tabular}


Para o segundo fator, essas variáveis aparecem como maiores contribuintes também, mas em ordem inversa: nível de aplicação, ano de adesão e setor, total de $70,45 \%$. As contribuições relativas dos componentes, a partir dos cossenos ao quadrado das dimensões, foram para a primeira dimensão: nível de aplicação B; mineração (Mine) entre os setores; ano de adesão 2008; e quanto à bolsa, mercado tradicional (MTD). A outra dimensão destaca: nível de aplicação A; adesão em 2007 e 2008; e novo mercado (IGC).

A Figura 3 traz a correspondência múltipla entre as variáveis (setor de atuação, ano de adesão, nível de aplicação das diretrizes, segmento na bolsa de valores e participação no ISE).

A análise dessa figura propicia as seguintes considerações:
- Empresas dos setores bancário (Banc) e de bens de consumo (BCon) há mais tempo efetuaram adesão à $\mathrm{GRI}$, atenderam em maior grau às diretrizes, possuem ações listadas no novo mercado e compõem o ISE;

- Indústria da construção (InCo) e outros (Outr) fizeram adesão mais recente às diretrizes (2008), publicaram seus relatórios com o menor nível de aplicação (C) ou simplesmente não declararam (D) e não possuem ações listadas na bolsa de valores;

- Energia (Ener) e serviços (Serv) apresentaram melhor distribuição em relação ao ano de adesão e nível de aplicação, porém muito ligados ao mercado tradicional BOVESPA.

A correspondência entre setores de atuação e ano de adesão (Figura 4) pelo eixo horizontal $(48,34 \%$ de informação) mostra que indústria da construção $(\mathrm{lnC}$ ) e outros (Outr) aderiram às diretrizes em 2008.

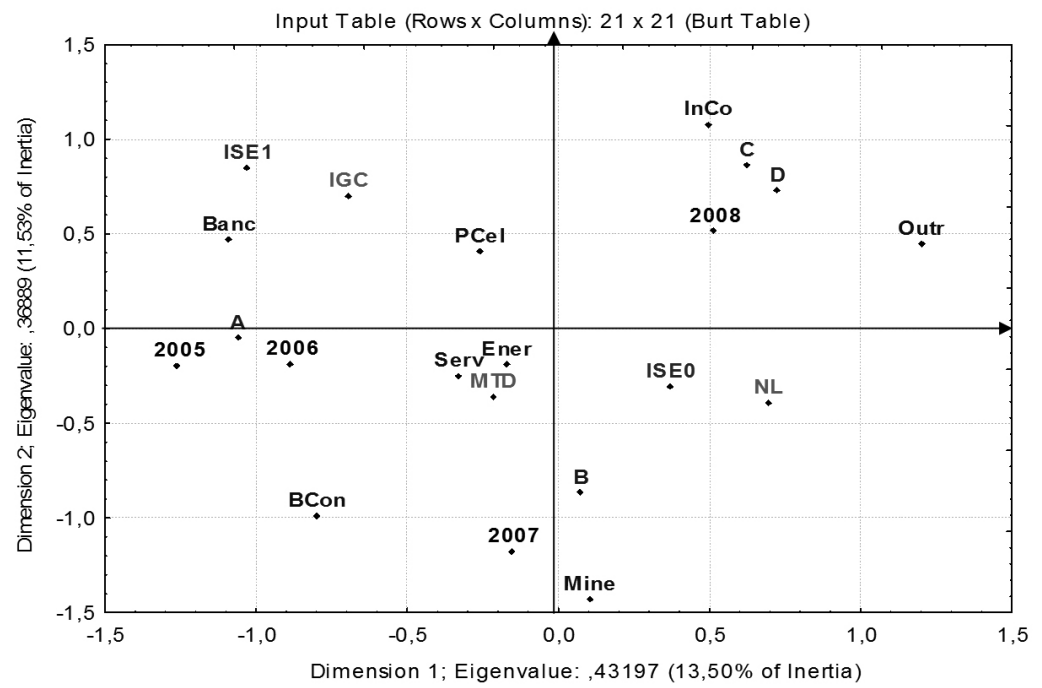

Figura 3. Setor de atuação $x$ ano adesão x nível de aplicação x segmento da BOVESPA x ISE. Fonte: dados da pesquisa.

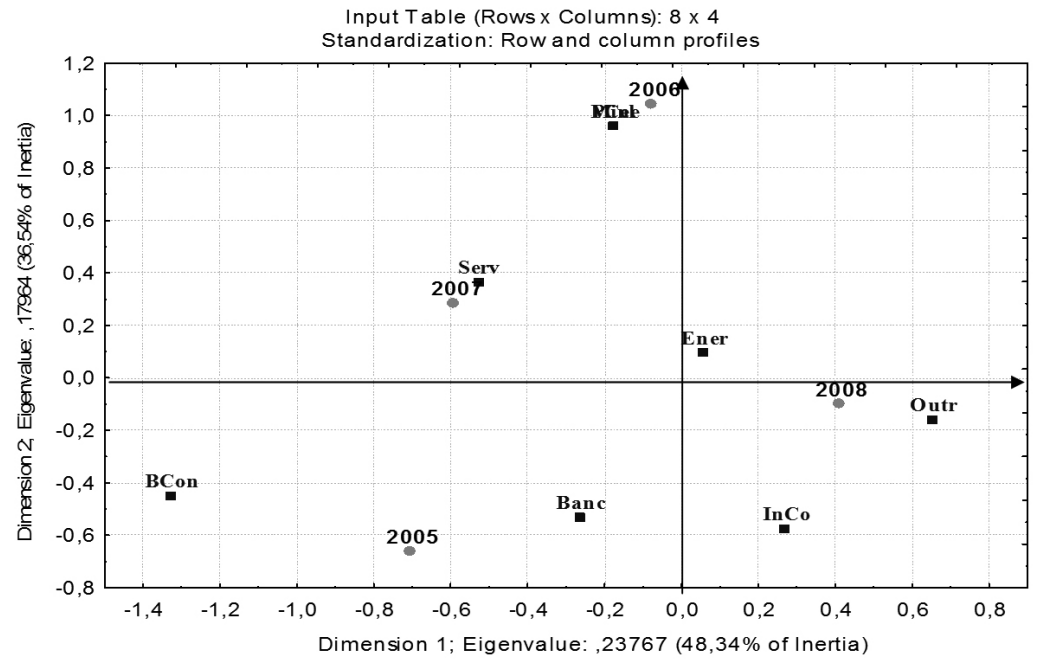

Figura 4. Setor de atuação econômica $x$ ano de adesão às diretrizes. Fonte: dados da pesquisa. 
Serviços (Serv) em 2007. Papel e celulose (PCel) e mineração (Mine) em 2006. Energia (Ener) possui distribuição próxima ao centro. No eixo vertical (36,54\% de informação), bens de consumo (BCon) e bancário (Banc) aderiram até 2005 ao GRI.

A correspondência entre setores de atuação e negociação na bolsa de valores (Figura 5), no eixo horizontal (54,37\% de recuperação), demonstra que bens de consumo (BCon) e outros (Outr) correspondem com ações não listadas (NL). Serviços (Serv) e bancário (Banc) correspondem com o novo mercado (IGC) e energia com o mercado tradicional (MTD).

A análise de correspondência entre os setores de atuação econômica e o nível de aplicação das diretrizes GRI (Figura 6), pelo eixo horizontal (47,51\% da informação), traz serviços (Serv), bancário (Banc) e bens de consumo (BCon) relacionados com o nível máximo (A) de aplicação das diretrizes. Energia (Ener) relaciona-se com o nível médio (B), porém próximo ao centro de gravidade. Indústria da construção (lnCo) e outros (Outr) relacionam-se com o menor nível (C). Papel e celulose (PCel) com a não declaração do nível de aplicação em seus relatórios (D). 0 eixo vertical (32,52\% da informação) mostra mineração (Mine) e energia (Ener) próximas do nível médio (B).

$A$ análise de correspondência entre 0 ano de adesão às diretrizes e o nível de aplicação das diretrizes ao modelo GRI (Figura 7), pelo eixo horizontal (63,54\% da informação), traz a formação de 3 grupos: a) as empresas que aderiram ao modelo da GRI até 2006 publicaram relatórios em 2008 seguindo as exigências do nível máximo de aplicação (A); b) as que aderiram em 2007 atenderam ao nível médio de aplicação (B); e c) as que iniciaram a publicação de relatórios em 2008 somente atenderam ao nível mínimo das exigências da GRI (C) ou não declararam o nível de aplicação adotado (D).

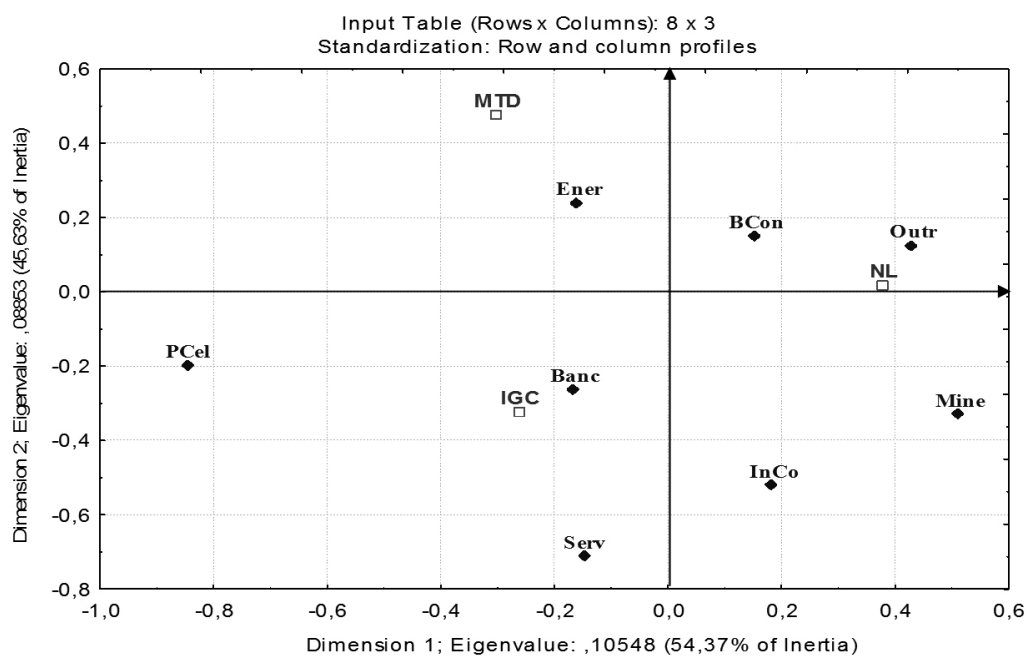

Figura 5. Setor de atuação econômica x segmento da bolsa de valores. Fonte: dados da pesquisa.

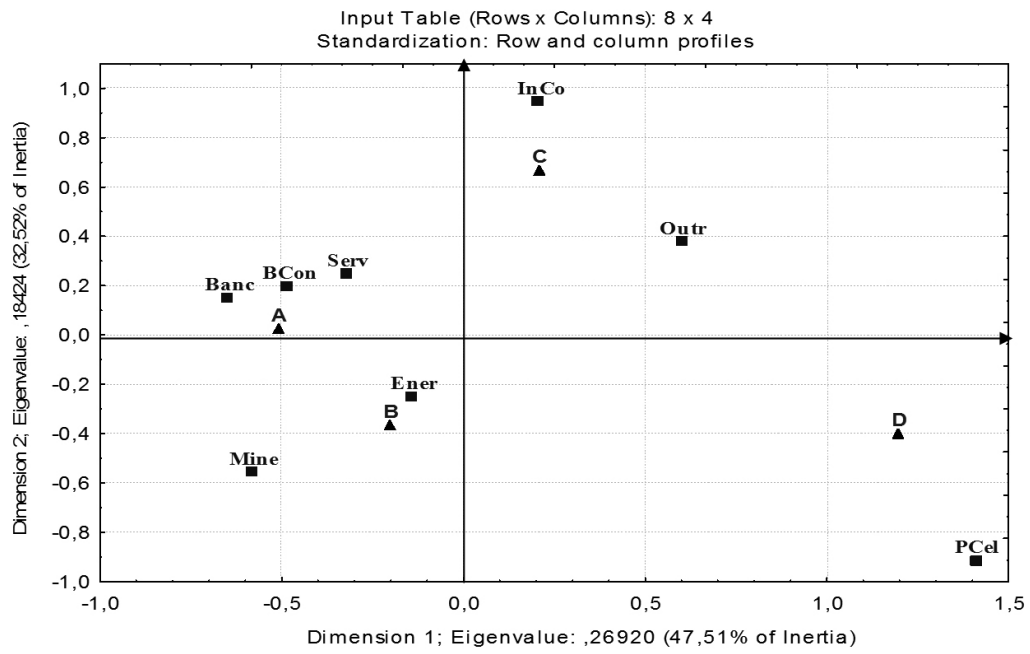

Figura 6. Setor de atuação econômica x nível de aplicação das diretrizes. Fonte: dados da pesquisa. 


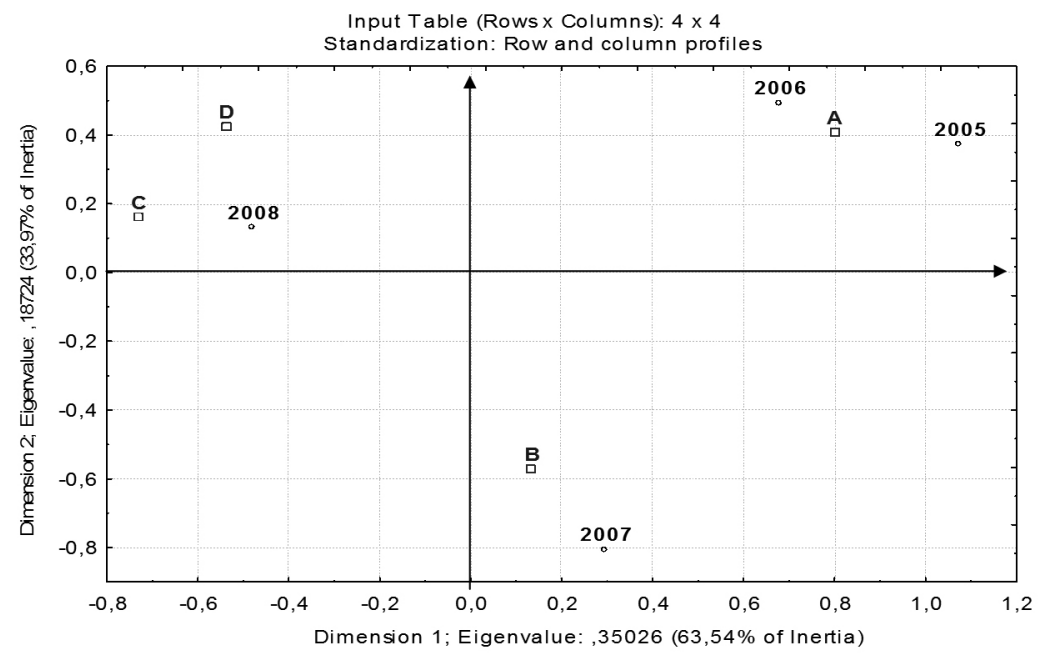

Figura 7. Ano de adesão às diretrizes x nível de aplicação das diretrizes. Fonte: dados da pesquisa.

\section{Considerações finais}

Este trabalho consistiu em uma análise descritiva sobre a publicação de balanços sociais ou relatórios de sustentabilidade empresarial, segundo os parâmetros da GRI, com o uso de pesquisa documental e dados secundários. As análises desenvolvidas permitem concluir que o universo de organizações que publicaram relatórios socioambientais até 2008 segundo o padrão GRl é bem reduzido, pouco mais de mil organizações. Contudo, se observa crescente adesão, demonstrada pelo número de publicações, sobretudo na Europa, continente vanguardista nesse processo. Salienta-se que essa iniciativa tem obtido sucesso e se tornou uma das principais iniciativas internacionais de estímulo às práticas de desenvolvimento sustentável empresarial em todo o globo.

$\mathrm{Na}$ América Latina esse movimento iniciou em 2000 e ganhou força em 2006. 0 total de publicações de relatórios no padrão GRI no período de 2000 a 2008 foi de 301 empresas, localizadas em 11 países da região. As empresas brasileiras respondem por metade do total publicado (148) no período, e somente no ano de 2008 foram 67 publicações. Porém, a adesão às diretrizes da GRI tanto no Brasil quanto na América Latina ainda é pequena em relação ao total de empresas existentes.

Com relação aos setores estudados, ocorre forte concentração no setor de energia, quase 35\% da amostra, e em mais 6 outros setores econômicos: bancário, bens de consumo, indústria de construção, mineração, papel e celulose e serviços. Constatou-se que as empresas do setor de energia apresentaram uma distribuição equilibrada em relação a todas as variáveis de pesquisa, sendo que, com relação ao ano de adesão, houve predominância de 2008. Nota-se que nesse ano empresas de 10 novos setores econômicos efetuaram publicação de seus relatórios, com isso se vislumbra tendência de disseminação dessa prática nos demais setores econômicos nacionais.

As análises efetuadas mostram que as empresas dos setores bancário e de bens de consumo aderiram à GRI há mais tempo e publicaram relatórios de modo mais completo e adequado ao nível de aplicação A das diretrizes em 2008. Além disso, apresentaram forte correspondência com as ações negociadas no segmento do novo mercado e de composição do ISE da BM\&FBOVESPA. Esse fato pode estar ligado à maior experiência adquirida em função do tempo de adesão e da internalização do processo de adequação às diretrizes, assim essas empresas procuram atender aos padrões exigidos, ficam mais seguras quanto ao atendimento dos requisitos de governança corporativa e melhor reconhecidas pelos investidores do mercado de capitais.

Outra consideração é que as empresas que aderiram ao modelo em 2008, mais relacionadas com os setores de indústria da construção e outros, publicaram seus relatórios com o menor nível de aplicação às diretrizes da GRI ou não declararam esse nível. Em sua maioria não possuem ações listadas em bolsa de valores. Estas condições podem ser vistas como referentes a um processo natural de aprendizagem e evolução institucional.

Esses fatos levam a questionar as informações limitadas que muitas vezes os relatórios sociais apresentam, assim como a falta de evidenciação das externalidades negativas das organizações, subjetividade na escolha dos itens a serem contemplados nos relatórios emitidos por cada organização e a falta de padronização, inclusive no que tange à periodicidade da informação. Isso dificulta a comparabilidade entre empresas e paises. Já que um objetivo primordial da criação da GRI 
consiste no desenvolvimento de diretrizes e métodos para relatar as ações de sustentabilidade empresarial com transparência, para que possam ser comparadas e valoradas por isso, questiona-se a ausência de padronização nos relatórios. Como transformar esses relatórios sociais em instrumentos de comunicação eficientes, uma vez que não há padronização e muitos apresentam informações desconexas, irrelevantes e que não esclarecem os verdadeiros desafios enfrentados pelas organizações?

A terceira versão GRI (G3) muito avançou nesse sentido, ao segregar o conteúdo do relatório em 3 categorias: (i) Perfil fornece informações de contextualização para o entendimento da organização, inclusive do seu desempenho geral, como, por exemplo, estratégia, perfil e governança; (ii) Forma de gestão descreve a forma como a empresa trata determinado tema ou conjunto de temas e serve para fornecer o entendimento do desempenho de uma área específica; e (iii) Indicadores de desempenho fornecem informações comparáveis sobre os desempenhos econômico, social e ambiental.

Por fim, a realização deste trabalho objetivou efetuar uma análise setorial a partir do fato da publicação de relatórios ou balanços sociais e do atendimento de critérios básicos definidos pela GRI. Desse modo, cabe aqui sugestão para novos estudos que possibilitem a verificação da qualidade dos dados e informações (indicadores) apresentados nos relatórios ou balanços sociais, haja vista que existem empresas que incorporam a sustentabilidade em seus processos de gestão como sendo diferencial estratégico. Todavia, outras apenas usam como instrumento mercadológico. Assim como se sugere a identificação de quais fatores influenciam a adesão à publicação de tais relatórios nos padrões da GRI. Outra sugestão é quanto à determinação dos motivos que levaram as empresas do setor de energia a terem um nível de adesão mais significativo do que os demais setores econômicos no país.

\section{Referências}

ALMEIDA, F. O bom negócio da sustentabilidade. Rio de Janeiro: Nova Fronteira, 2002.

ANDRADE, M. A. M.; GOSLING, M.; XAVIER, W. S. Por trás do discurso socialmente responsável da siderurgia mineira. Produção, v. 20, n. 3, set. 2010. Disponível em: <http:// www.scielo.br/scielo.php?script=sci_arttext\&pid=S0103$65132010000300010 \& \operatorname{lng}=p t \& n r m=i s o>$. Acesso em: 06 jan. 2011.

ASHLEY, P. A. (Coord.). Ética e responsabilidade social nos negócios. São Paulo: Saraiva, 2002.

AZEVEDO, A. L. V. Indicadores de sustentabilidade empresarial no Brasil: uma avaliação do Relatório do CEBDS. Revista lberoamericana de Economía Ecológica, v. 5, p. 75-93, 2006. Disponivel em: <http://www.redibec. org/lV0/rev5_06.pdf>.
BASSETTO, L. I. A incorporação da responsabilidade social e sustentabilidade: um estudo baseado no relatório de gestão 2005 da companhia paranaense de energia - COPEL. Gestão \& Produção, v. 17, n. 3, 2010. Disponível em <http://www.scielo.br/scielo php?script=sci_arttext\&pid=S0104-530X201000030001 $6 \& \operatorname{lng}=$ pt\&nrm=iso>. Acesso em: 06 jan. 2011.

BELLEN, H. M. V. Indicadores de sustentabilidade: uma análise comparativa. Rio de Janeiro: Editora FGV, 2007.

BM\&FBOVESPA. Bolsa de Valores, Mercadorias e Futuros S.A. Disponível em: <http://www.bmfbovespa.com.br/ portugues/home.asp>. Acesso em: 28 set. 2009.

BOVESPA. Bolsa de Valores de São Paulo S.A. Disponível em: <http://www.bovespa.com.br/Principal.asp>. Acesso em: 23 set. 2009.

BROWN, H. S., DE JONG, M., LEVY, D. L. Building institutions based on information disclosure: lessons from GRI's sustainability reporting. Journal of Cleaner Production, v. 17, n. 6, p. 571-580, 2009. http://dx.doi.org/10.1016/j. jclepro.2008.12.009

CASTRO, F. A. R.; SIQUEIRA, J. R. M.; MACEDO, M. A. S. Análise da utilização dos indicadores essenciais da versão "G3", da Global Reporting Initiative, nos relatórios de sustentabilidade das empresas do setor de energia elétrica sul americano. In: SIMPÓSIO DE ADMINISTRAÇ̃̃O DE PRODUÇÃO, LOGÍSTICA E OPERAÇÕES INTERNACIONAIS, 2009, Rio de Janeiro. Anais... Rio de Janeiro, 2009.

CERTO, S. C.; PETER, J. P. Administração Estratégica: planejamento e implantação da estratégia. São Paulo: Makron Books, 1993.

CORNELIUS, N., WALLACE, J., TASSABEHJI, R. An analysis of corporate social responsibility, corporate identity and ethics teaching in business schools. Journal of Business Ethics, v. 76, p. 117-135, 2007. http://dx.doi. org/10.1007/s10551-006-9271-6

DAUB, C. H. Assessing the quality of sustainability reporting: an alternative methodological approach. Journal of Cleaner Production, v. 15, p. 75-85, 2007. http://dx.doi. org/10.1016/j.jclepro.2005.08.013

ETHOS. Instituto Ethos de Empresas e Responsabilidade Social. Apresenta os indicadores de responsabilidade social nas empresas. São Paulo, 2009. Disponível em: <http://www.ethos.org.br/indicadores/>. Acesso em: 21 set. 2009.

ETHOS. Indicadores Ethos de Responsabilidade Social empresarial. 2008. Disponivel em: <http://www.ethos.org. br/_Uniethos/documents/INDICADORESETHOS2008PORTUGUES.pdf>. Acesso em: 23 mar. 2010.

FERREIRA, L. F. et al. Indicadores de sustentabilidade empresarial: uma comparação entre os indicadores do balanço social IBASE e relatório de sustentabilidade segundo as diretrizes da global reporting initiative GRI. In: SIMPÓSIO DE EXCELÊNCIA EM GESTÃO E TECNOLOGIA, 2009, Resende. Anais... Resende, 2009.

GASPARINO, M. F.; RIBEIRO, M. S. Análise de relatórios de sustentabilidade, com ênfase na GRI: comparação entre empresas do setor de papel e celulose dos Estados Unidos e Brasil. Revista de Gestão Social e Ambiental, v. 1, n. 1, p. 102-115, 2007.

GLOBAL REPORTING INITIATIVE - GRI. Diretrizes para relatório de sustentabilidade. versão 3.0. São Paulo: GRI, 2006.

GLOBAL REPORTING INITIATIVE - GRI. Disponivel em: <http:// www.globalreporting.org/Home/WhatWeDoPortuguese. htm>. Acesso em: 13 ago. 2009. 
GLOBAL REPORTING INITIATIVE - GRI. Latest Guidelines. São Paulo: GRl, 2012. Disponível em: <https://www. globalreporting.org/reporting/latest-guidelines/g4developments/Pages/default.aspx>. Acesso em: 20 apr. 2012.

HAIR JUNIOR, J. F. et al. Análise multivariada de dados. 5. ed. Porto Alegre: Bookman, 2005.

INTERNATIONAL INSTITUTE FOR SUSTAINABLE DEVELOPMENT - IISD. Sustainable development indicators. 1ISD, 2005. Disponível em: <http://www. iisd.org/pdf/2005/measure_indicators_sd_way_forward. pdf>. Acesso em: 23 mar. 2010.

KRAJNC, D.; GLAVIC, P. Indicators of sustainable development. Clean Technology Environment Policy, n. 5, p. 279288, 2005.

LABUSCHAGNE, C.; BRENT, A. C.; ERCK, R. P. G. Assessing the sustainability performance of industries. Journal of Cleaner Production, v. 13, n. 4, p. 373-385, 2005. http:// dx.doi.org/10.1016/j.jclepro.2003.10.007

LEVY, D. L.; SZEJNWALD-BROWN, H.; DE JONG, M. The Contested politics of corporate governance the case of the global reporting initiative. Business \& Society, v. 49, n. 1, p. 88-115, 2010. http://dx.doi. org/10.1177/0007650309345420

MARIMON, F. et al. The worldwide diffusion of the global reporting initiative: what is the point? Journal of Cleaner Production, v. 33, p. 132-144, 2012. http://dx.doi. org/10.1016/j.jclepro.2012.04.017

MELÉ, D.; DEBELJUH, P.; ARRUDA, M. C. Corporate ethical policies in large corporations in Argentina, Brazil and Spain. Journal of Business Ethics, v. 63, p. 21-38, 2006. http://dx.doi.org/10.1007/s10551-005-7100-y

MINGOTI, S. A. Análise de dados através de estatística multivariada: uma abordagem aplicada. Belo Horizonte: Editora UFMG, 2005.

OLIVEIRA, M. C. et al. Disclosure of social information by Brazilian companies according to United Nations indicators of corporate social responsibility. Revista Contabilidade e Finanças, São Paulo, v. 20, n. 51, 2009. Disponível

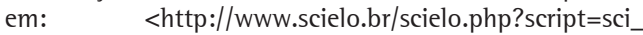
arttext\&pid=S1519-70772009000300008\&lng=pt\&nrm =iso>. Acesso em 06 jan. 2011.
PARK, J.; BRORSON, T. Experiences of and views on thirdparty assurance of corporate environmental and sustainability reports. Journal of Cleaner Production, v. 13, p. 1095-1106, 2005. http://dx.doi.org/10.1016/j. jclepro.2004.12.006

PEREIRA, R. S.; FARIA, A. C.; SOUZA, M. T. S. Análise dos indicadores de sustentabilidade no segmento químico e petroquímico. In: ENCONTRO DA ASSOCIAÇÃO NACIONAL DE PÓS-GRADUAÇÃO E PESQUISA EM ADMINISTRAÇÃO, 33., 2009, São Paulo. Anais... São Paulo: ANPAD, 2009.

PRADO-LORENZO, J. M.; GALLEGO-ALVAREZ, I.; GARCIASANCHEZ, 1. M. Stakeholder engagement and corporate social responsibility reporting: the ownership structure effect. Corporate Social Responsibility and Environmental Management, v. 16, p. 94-107, 2009. http://dx.doi. $\operatorname{org} / 10.1002 /$ csr. 189

SEARCY, C.; KARAPETROVIC, S.; McCARTNEY, D. Designing sustainable development indicators: analysis for a case study. Measuring Business Excellence, v. 9, n. 2, p. 3341,2005.http://dx.doi.org/10.1108/13683040510602867

SIKDAR, S. K. Sustainable development and sustainability metrics. American Institute of Chemical Engineers Journal, v. 49, n. 8, p. 1928-1932, 2003. http://dx.doi. org/10.1002/aic.690490802

SKOULOUDIS, A., EVANGELINOS, K., KOURMOUSIS, F. Development of an evaluation methodology for triple bottom line reports using international standards on reporting. Environmental Management, v. 44, p. 298311, 2009. http://dx.doi.org/10.1007/s00267-009-9305-9

SOUZA, E. G.; ANDRADE, E. 0.; CÂNDIDO, G. A. Estudo exploratório nos municípios produtores de leite bovino no estado da Paraíba. REAd, v. 14, n. 3 set-dez, 2008. Edição 61.

SUSTAINABILITY LTD.; FUNDAÇ̃̃O BRASILEIRA PARA 0 DESENVOLVIMENTO SUSTENTÁVEL - FBDS; PROGRAMA DAS NAÇÕES UNIDAS PARA O MEIO AMBIENTE - PNUMA. Rumo à credibilidade. dez. 2008. Disponivel em: <http://www.empresaverde.globolog. com.br/Relatorio_FBDS_internet1.pdf>. Acesso em: 13 ago. 2009.

\title{
Sustainability reporting according to the Global Reporting Initiative (GRI): a correspondence analysis between the Brazilian economic sectors
}

\begin{abstract}
This article aims to present the level of adhesion and publication volume of sustainability reports of Brazilian companies according to the Guidelines of the Global Reporting Initiative (GRI) between 2000 and 2008. For the analysis, five variables were defined: i) Economic Sector of companies; ii) Year of adhesion; iii) Application Level Guidelines; iv) Existence of Shares Traded at BMF\&BOVESPA; and v) Participation in Composition of the Corporate Sustainability Index (ISE) of BMF\&BOVESPA. As regards the methodological procedures were applied single and multiple analyzes by correspondence between the sectors of economic activity and the 5 variables of studies defined. The results show that the number of organizations that have published environmental reports through 2008 is low. However, there is growing acceptance elsewhere, mostly in Europe, as demonstrated by the number of publications. Brazilian companies accounted for half of the volume of publications in 2008 in Latin America, and the energy sector led this process, comprising 35\% of the sample.
\end{abstract}

Keywords

Sustainability reporting. Economic sectors. GRI guidelines. 